\title{
ANTIFUNGAL PROPERTIES OF WATER EXTRACT PROPOLIS COATING AGAINST ANTHRACNOSE (Colletotrichum gloeosporioides) DISEASE ON STRAWBERRY (Fragaria anannassa)
}

\author{
NURUL ATHIRAH OMAR, SITI NORDAHLIAWATE MOHAMED SIDIQUE and \\ FAUZIAH TUFAIL AHMAD*
}

\author{
Faculty of Fisheries and Food Science, Universiti Malaysia Terengganu, \\ Kuala Nerus 21030, Terengganu, Malaysia \\ *E-mail: fauziah.tufail@umt.edu.my
}

Accepted 10 December 2020, Published online 25 December 2020

\begin{abstract}
Anthracnose is a major pre and post-harvest disease. Due to the consumer concerns of the residual effect of the synthetic fungicide, biocontrol from a natural source is highly required by the consumer to reduce the problem. Propolis is a natural antifungal that can be used as a coating to control fruit quality and postharvest losses. This study evaluated the physical and chemical characteristics of strawberry (Fragaria ananassa) induced with Colletotrichum gloeosporioides, coated with water extract propolis (WEP) and stored at $5^{\circ} \mathrm{C}$. The effect of coating was evaluated with different concentrations of water extract propolis (WEP) which were control, 10\%, 12\%, and 14\%. The post-harvest parameters such as weight loss, total soluble solids (TSS), anthocyanin, disease severity index (DSI), and firmness were evaluated at two days interval for 12 days of storage. The highest percentage of inhibition (in vitro) was shown by the highest concentration of WEP (14\%). Fruits coated with propolis showed reduced deterioration and infection diameter of fungus, as compared to the control (without coating) which already spoiled at day 4 . Strawberry coated with $14 \%$ concentration of WEP also showed the highest firmness compared to other treatments. Thus, this coating can be used as an alternative method for bio-control of disease to reduce the postharvest loss of fresh produce.
\end{abstract}

Key words: Propolis, stingless bee, antifungal, anthracnose, strawberry, post-harvest quality

\section{INTRODUCTION}

Strawberry (Fragaria ananassa) is one of the perishable fruit, especially after harvest. The main causes of strawberry deterioration during storage are the development of rots that are caused by a range of fungi (Feliziani \& Romanazzi, 2016). The most fungus that causes postharvest losses on strawberries is Colletotrichum species associated with strawberry anthracnose (Ellis \& Erincik, 2008). The symptom randomly distributed gray to black spots caused by Colletotrichum fragariae or Colletotrichum gloeosporioides (Suzuki et al., 2010). Colletotrichum gloeosporioides, is one of the world's most important pathogens that cause anthracnose to most fruit (Phoulivong et al., 2010). Anthracnose is a major pre and post-harvest disease. However, fungicide schedule applications do not always result in efficient and the increasing of the

\footnotetext{
* To whom correspondence should be addressed.
}

fungi resistance to some active principles has been reported (Kososki et al., 2001). Rapid and constant cold storage added with coating may help in reducing the growth rate of microorganisms in strawberries (Ribeiro et al., 2007; Feliziani \& Romanazzi, 2016). To date, there was a limited study on the biological control reported on reducing the anthracnose on strawberries especially from agriculture by-products such as propolis. Currently, there is an increasing interest in the use of organic compounds such as propolis as edible fruit coating because of its potential to inhibit fungal growth and extend the shelf life of fruits (Awawdeh et al., 2009). Propolis which was reported with excellent properties of anti-inflammatory, antibacterial, antiviral, immunomodulatory, antioxidant, and antiproliferative may act as the control for anthracnose (Viuda et al., 2008). There was almost no study reported on the stingless bee propolis as fruit coating. However, Ahmad et al. (2019) has reported on the great antimicrobial properties of 
propolis from stingless bee towards most of the food pathogen. Besides, a study was done by Zahid et al. (2013) emphasized the artepillin-C as the bioactive constituent form in propolis that related to the extremely potent antifungal properties of propolis. All of these studies indicate that stingless bee propolis has a high potential to be used as fruit coating too to reduce the fungal disease during storage. Thus, this study aims to study the potential of propolis from the stingless bee as an antifungal agent in reducing the anthracnose disease on the strawberry while maintaining the post-harvest quality during storage.

\section{MATERIALS AND METHODS}

\section{Sample preparation}

Raw propolis was collected from beehives located at Institut Perguruan Malaysia, 22200 Besut, Terengganu. Samples were cleaned by removing dead beed or any contamination and stored at $-20^{\circ} \mathrm{C}$ for $20 \mathrm{~min}$ (Sun et al., 2015). Frozen propolis was grinded into a fine powder.

Strawberries with uniform size and color $(75 \%$ red surface), free of physical damage and fungal were collected from Farm Agro Highland, Cameron Highland. Strawberries were washed using acetic acid (3\%) and rinsed with distilled water and left airdried at ambient temperature.

\section{Water extraction of propolis}

A total of $400 \mathrm{~g}$ of propolis powder was homogenized with $1000 \mathrm{~mL}$ of water at $50^{\circ} \mathrm{C}$ (Thomas et al., 2016). The filtered extract was placed into a $50 \mathrm{~mL}$ Falcon tube and centrifuged at $10000 \mathrm{rpm}$ for $10 \mathrm{~min}$ to obtain the supernatant. The supernatant was dried with a rotary evaporator $\left(40^{\circ} \mathrm{C}\right)$. The paste was evaporated in a vacuum oven at a temperature of $60^{\circ} \mathrm{C}$ to obtain dry water extract propolis (Paviani et al., 2012) and diluted with sterilized water, to produce the concentration of $10 \%, 12 \%$, and $14 \%$ of water extract propolis (WEP).

\section{Antimicrobial analysis (in vitro)}

The antimicrobial analysis of water extract propolis (WEP) against Colletotrichum species was done using the poisoned plate technique (in vitro). Poison plate is a standard method that is normally used to determine the inhibitory effect of plant extract against fungal species such as Colletotricum sp. This method was done by placing the isolate of the fungus onto the agar mixed with extract and the inhibitory effect was observed after the incubation period (Das et al., 2010). In this study, the identified Colletotrichum sp. of strawberry was grown onto Potato Dextrose Agar (PDA). The culture was flooded with sterile distilled water and dislodged the spore using a glass rod. The spore suspensions obtained were passed through filtration of sterile cheesecloth to remove mycelial fragments (Lane et al., 2012). Spore suspension $\left(2 \times 10^{6}\right.$ conidia $\left./ \mathrm{mL}\right)$ was obtained by using a Haemocytometer (SigmaAldrich) counting. Different concentrations; $10 \%$ WEP (v/v), 12\% WEP (v/v) and 14\% WEP (v/v) was added into PDA and to solidify and tested against Colletotrichum sp. A $5 \mathrm{~mm}$ disc from seven days old of Colletotrichum cultures was plucked out and transferred to the middle of PDA and incubated at $28 \pm 2{ }^{\circ} \mathrm{C}$ for a week. The growth of the fungal colony was recorded. The absence of growth in the plate indicates the effectiveness of plant extract against the test. The two readings in the control and treatments was transformed into percent inhibition (\%) of radial growth by using the following formula (Marinho et al., 2018):

Formula 1:

$$
\text { mycelium inhibition }=\frac{(C-T)}{C} \times 100
$$

Explanation:

$\mathrm{C}=$ colony diameter $(\mathrm{mm})$ growth in the control.

$\mathrm{T}=$ colony diameter $(\mathrm{mm})$ growth in the treatment .

Application of propolis on strawberries (in vivo)

Strawberries were dipped for 2 min into water extract propolis (WEP) containing 10\%, 12\%, and $14 \%$. All samples were inoculated by spraying prepared spore suspension of $3 \times 10^{6}$ conidia/mL of Colletotrichum gloeosporioides. All inoculated and treated samples were kept at ambient temperature and analyzed at a 2-day interval for 12 days of storage for post-harvest quality.

\section{Post-harvest analysis}

All samples were analyzed for post-harvest quality to determine the effect of coating (in vivo) from WEP on the fruit quality during storage. The post-harvest analysis was weight loss, total soluble solids, firmness, disease severity assessment, and anthocyanin. Weight loss of strawberry was done to see if the coating from WEP reduced the anthracnose occurrence then the respiration will be reduced and weight loss will be delayed. Weight loss was determined using an electronic balance (A \& D Model HT-500). The result was expressed as a percentage of weight loss (\%) according to the following formula (López-Castañeda et al., 2010):

Formula 2:

$\%$ Weight loss $=\frac{(\text { initial weight }- \text { final weight })}{\text { initial weight }} \times 100$ 
Table 1. Scale for disease severity assessment (Priyadarshanie \& Vengadaramana, 2015)

\begin{tabular}{cll}
\hline Disease scale & Description & Inference \\
\hline 0 & No symptoms on fruits & No infection \\
1 & $1-25 \%$ of the inoculated area covered with lesion & Mild infection \\
2 & $26-50 \%$ of the inoculated area covered with lesion & Moderate infection \\
3 & $51-75 \%$ of the sample are infected and softening & Severe infection \\
4 & $>76 \%$ and rotting & Very severe/ devastating \\
\hline
\end{tabular}

The total soluble solids (Brix) were determined using a handled refractometer (Atago, MODEL REF 103) to determine the sweetness of the fruit. The fruit firmness was determined using TAPlus Texture Analyser (Stable Micro Systems) and the result was expressed as newton $(\mathrm{N})$. Fruit firmness analysis is important to determine the freshness of the strawberries during storage with the disease. Disease severity assessment of the fruit was determined by observing the diameter lesion of anthracnose. The assessment was done based on the given scale (Table 1).

The overall disease severity index (DSI) was calculated as follows (Mak et al., 2004):

Formula 3:

$\operatorname{DSI}(\%)=\frac{\begin{array}{c}\sum \text { (number of symptomatic fruits } x \\ \text { severity index })\end{array}}{N \times Z} \times 100$

$\mathrm{N}=$ Total of sample fruits.

$\mathrm{Z}=$ Highest rating scale.

The total anthocyanin content (TAC) was determined by the $\mathrm{pH}$-differential method (Giusti \& Wrolstad, 2001). Fruit (5 g) was grind with $10 \mathrm{~mL}$ methanol and centrifuged (5000 rpm, $\left.10 \mathrm{~min}, 2^{\circ} \mathrm{C}\right)$. After adjustment of the sample with $\mathrm{pH}$ buffer (pH 1.0 with $\mathrm{KCL}$ and $\mathrm{pH} 4.5$ with $\mathrm{CH}_{3} \mathrm{COONa}$ ), the extracted solution was then read using a spectrophotometer (Shimadzu UV-1800). The concentration of TAC was calculated based on the following formula (Damsa et al., 2016):

Formula 4:

$$
A=\left(A_{510^{-}} A_{700}\right)_{p H 1.0}-\left(A_{510^{-}} A_{700}\right)_{p H 4.5}
$$

Monomeric anthocyanin $=(A \times M W \times D F \times 100) / \mu / L$

\section{Pigment $(\mathrm{mg} / \mathrm{L})$}

$\mathrm{A}=$ Absorbance.

$\mathrm{MW}=$ Molecular weight (484.84 g/mol for cy-3-glu). $\mathrm{DF}=$ Dilution factor.

$\varepsilon=$ Molar extinction coefficient (34300 for cy-3-glu). $\mathrm{L}=$ Path length.

\section{Statistical analysis}

The experimental design for this study is a complete randomized design (CRD). The data were subjected to analysis of variance (ANOVA) using IBM SPSS 23.

\section{RESULTS AND DISCUSSION}

\section{Mycelium inhibition (\%)}

The inhibition of Colletotrichum gloesporioides mycelium was increased with the increment of concentration of water extract propolis after a week incubation (Table 2 and Figure 1). The slower growth of tested fungi in the plate indicates the effectiveness of WEP against the fungi. The results are in agreement with an earlier study by Bussaman et al. (2012) who reported the increasing concentration of plant extract reduced the mycelial growth of C. gloeosporioides. A study by Kim et al. (2014) also showed the reduction of mycelial growth of C. gloeosporioides with Streptomyces sp. Results from this study also showed a similar percentage $(\%)$ of mycelial inhibition with the study by Kim et al. (2014). But, all of these previous studies use methanol extract while this current study used water extract. Water extract of the plant normally was reported with lower antifungal properties compared to methanol and other organic solvents (Jabeen and Javaid, 2008). The great antimicrobial properties of water extract propolis (WEP) as fruit coating in this study may be contributed by the high content of phenolic compounds in propolis (Ahmad et al., 2019). There are many studies reported on the positive

Table 2. Percentage of mycelium inhibition (\%) using different concentration of water extract propolis concentration on PDA after 7 days of incubation

\begin{tabular}{cc}
\hline Treatment & $\%$ Mycelium inhibition \\
\hline $0 \%$ (Control) & 21.95 \\
$10 \%$ & 39.2 \\
$12 \%$ & 41.46 \\
$14 \%$ & 48.78 \\
\hline
\end{tabular}




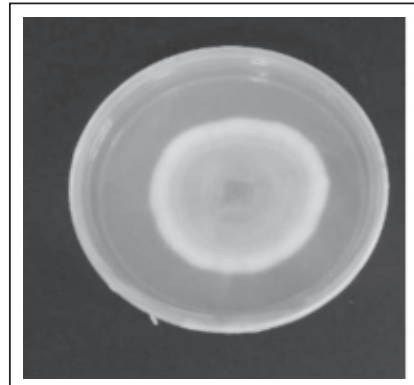

$0 \%$ (Control)

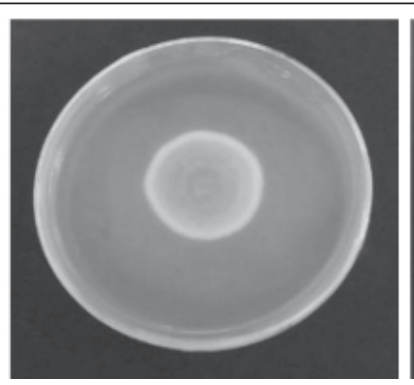

$10 \%$

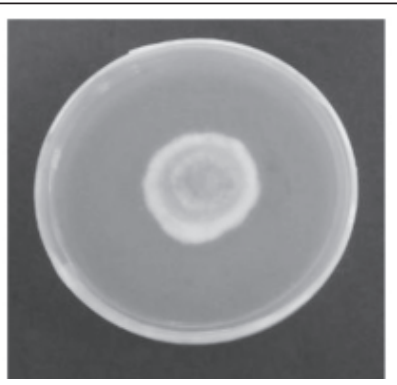

$12 \%$

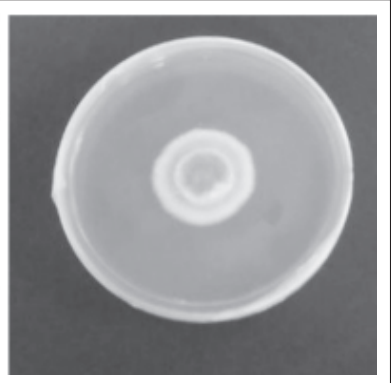

$14 \%$

Fig. 1. The inhibition zone of Colletotrichum gloesporioides on poison plate with different concentration of WEP.

relationship between the antimicrobial properties and phenolic compounds (Alves et al., 2014; Ahmad et al., 2019) such as cinnamic acid, taxifolin, chlorogenic acid, and chicoric acid (Qadir et al., 2017). Besides, the presence of pinocembrin, galangi, and pinobankin in the flavonoid of propolis was also had antimicrobial properties (Park et al., 1998).

\section{Water loss}

Although the trend of weight loss of coated strawberry with WEP in Figure 2 showed a lower value there was no significant difference $(p>0.05)$ between treatments. The physical appearance of non-coated fruit (Figure 7) showed severe infection of fungal but looks like it did not significantly affect the weight. This is maybe due to the propolis coating mixture which only consists of WEP and sterilized distilled water. The WEP is effective in reducing the anthracnose disease (Figure 6) but not sufficient to delay the water loss significantly. However, on day 12, the weight loss of fruit coated with $14 \%$ of WEP showed lower weight loss. This is due to the antifungal properties of WEP which delay the respiration rate of the fruit due to the infection by the fungus. Besides, the hydrophobic character of the propolis also resulted in a lower water reduction through transpiration and respiration (Barrera et al., 2015).

\section{Firmness}

Figure 3 showed the firmness of coated fruit (with WEP) was higher than the uncoated $(p<0.05)$ during storage. Theoretically, firmness was correlated with respiration where carbohydrate was broken down by hydrolytic enzymes such as pectin methylesterase (PME) and polygalacturonase (PG) which results in a reduction of firmness during respiration (Chitarra et al., 2005). So, this hypothesis correlated with this study which showed the hydrophobic characteristic of propolis that can reduce the respiration and transpiration and subsequently reduce the loss of firmness. In addition to that, a study by Anjum et al. (2019) found that propolis rich with wax which makes contributes to the hydrophobic characteristic.

\section{Total soluble solids}

Theoretically, total soluble solids (TSS) of fruit increased with the advancement of ripening of fruits irrespective of maturity condition (Moneruzzaman et al., 2009). Any treatment that can delay the ripening during storage should result in lower TSS. However, in this study, there was no significant difference $(p>0.05)$ reported for coated and noncoated strawberries (Figure 4) indicated that coating with WEP did not significantly delay the ripening of the fruit. The lower trend of TSS with the storage also showed that the ripening is not occurred as usual which may be affected by the infection of the disease.

\section{Anthocyanin}

The amount of anthocyanin (TAC) is important for the attractiveness and maturity assessments of strawberries. The result showed that TAC (Figure 5) was not affected by the application of WEP of the fruit $(p>0.05)$. All treatments showed similar anthocyanin values during storage. The decreasing trend of anthocyanin may due to the fungistatic properties which secrete secondary metabolite which capable to degrade any phenolic compounds (Daayf \& Lattanzio, 2008).

\section{Percentage of disease severity (DSI)}

Potential propolis as an antifungal agent could be potentially exploited in controlling the growth of phytopathogenic fungi during post- and preharvest (Meneses et al., 2009). There is a reduction in the severity of disease with increasing of WEP concentration (Figure 6). The disease severity of fruit was clearly shown in Figure 7 which indicates the negative result for Colletotrichum gloesporioides on all samples. All fruits did not show the symptom of Colletotrichum gloesporioides which distributed gray to black spots (Suzuki et al., 2010). However, there was another symptom that appears on the fruits (water-soaked with white, 


\section{Weight loss}

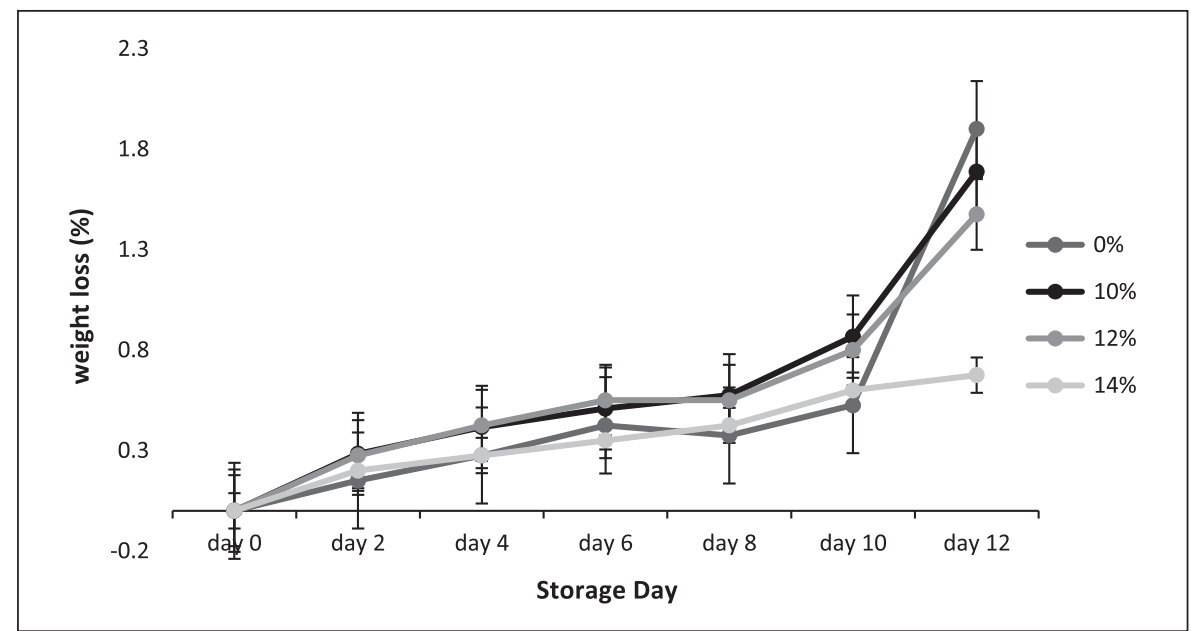

Fig. 2. Effect of the different water extract propolis concentration on the percentage of weight loss of strawberry.

\section{Firmness}

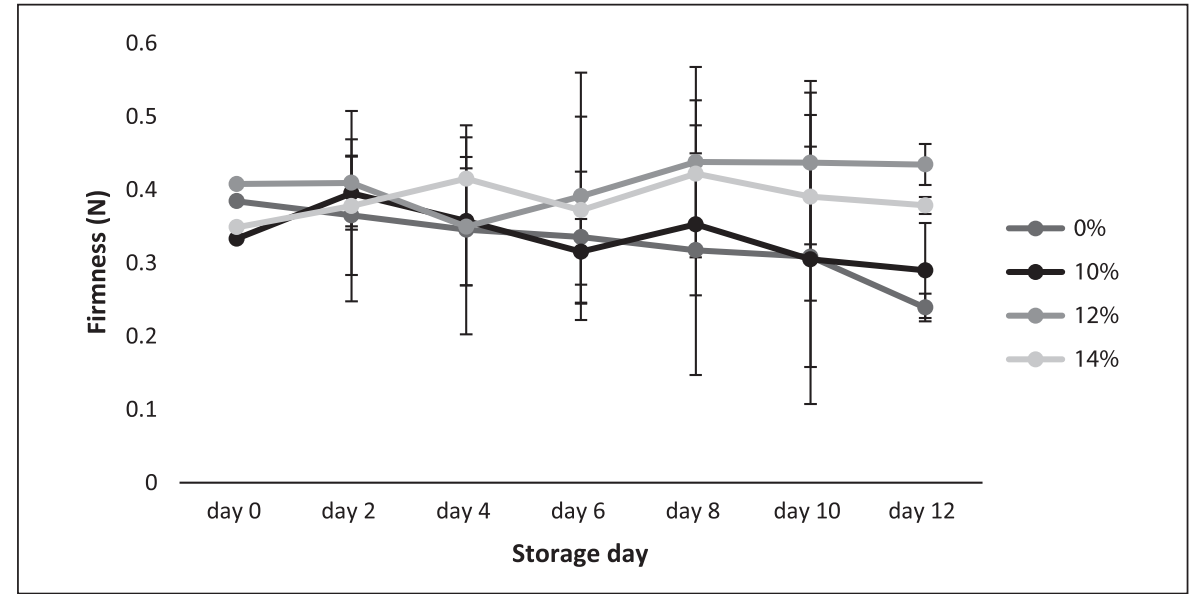

Fig. 3. Effect of the different water extract propolis as a coating on the firmness of strawberry.

Total soluble solids (TSS)

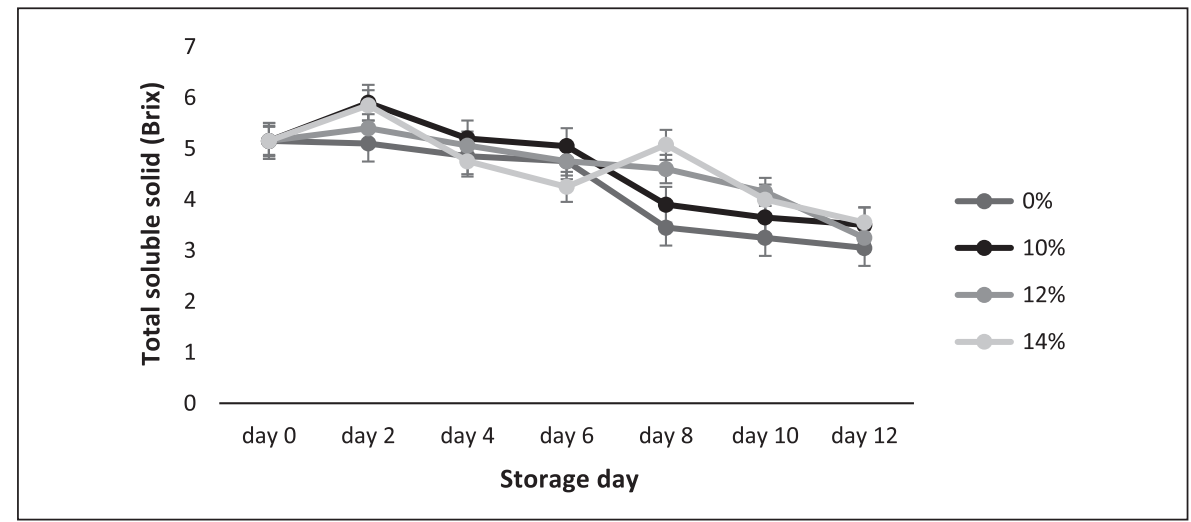

Fig. 4. Effect of different water extract propolis concentration as a coating on the soluble solid of strawberry. 


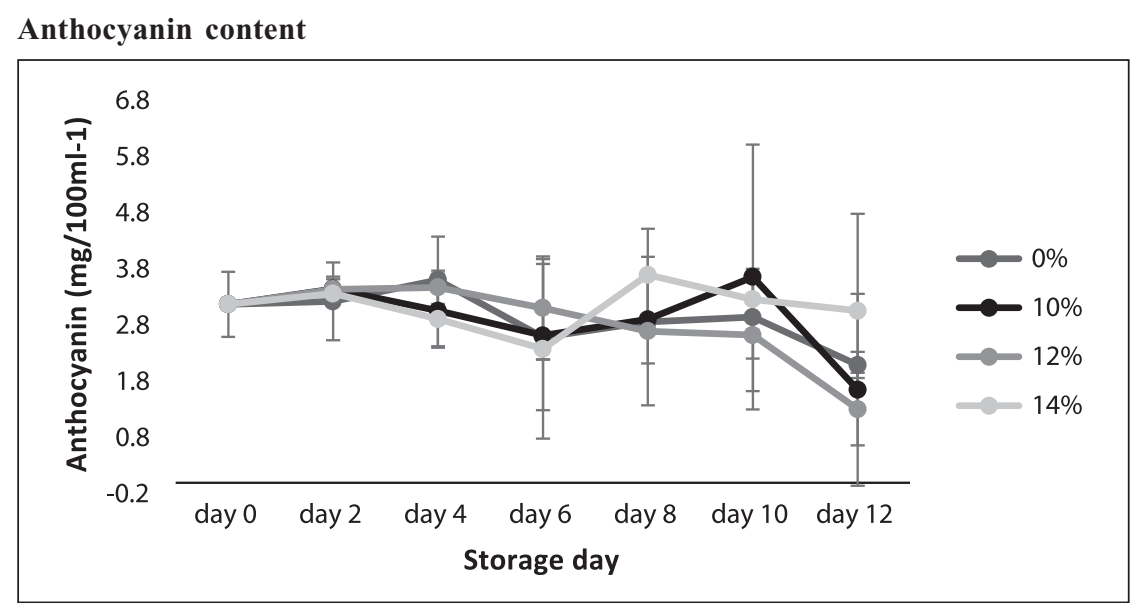

Fig. 5. Effect of different water extract propolis concentration as a coating on the anthocyanin content of strawberry.

\section{Disease severity index (\%)}

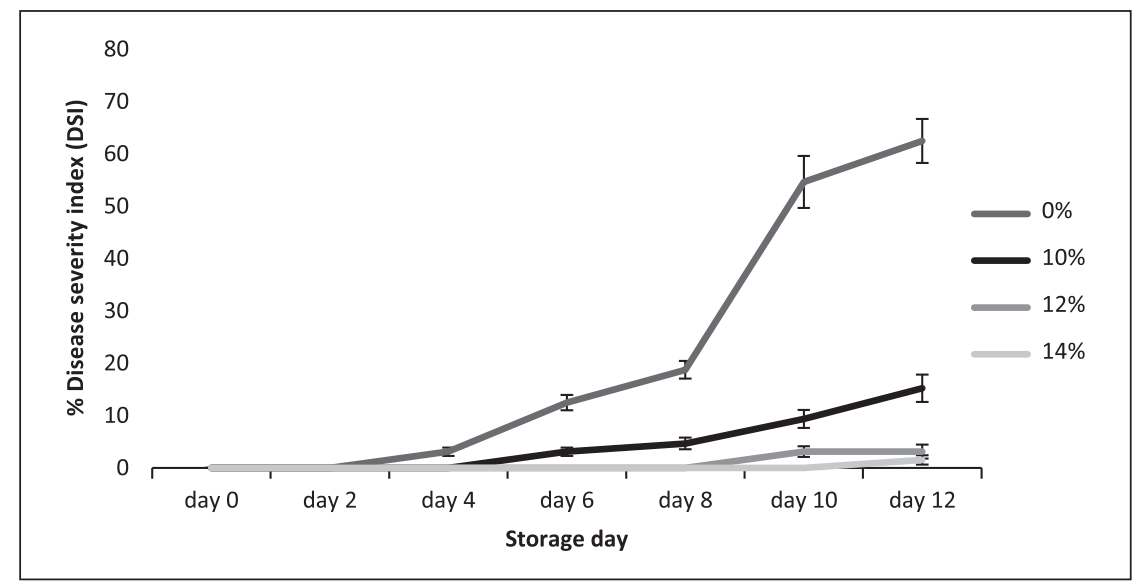

Fig. 6. Effect of different water extract propolis concentration on reducing the percentage severity on strawberry.
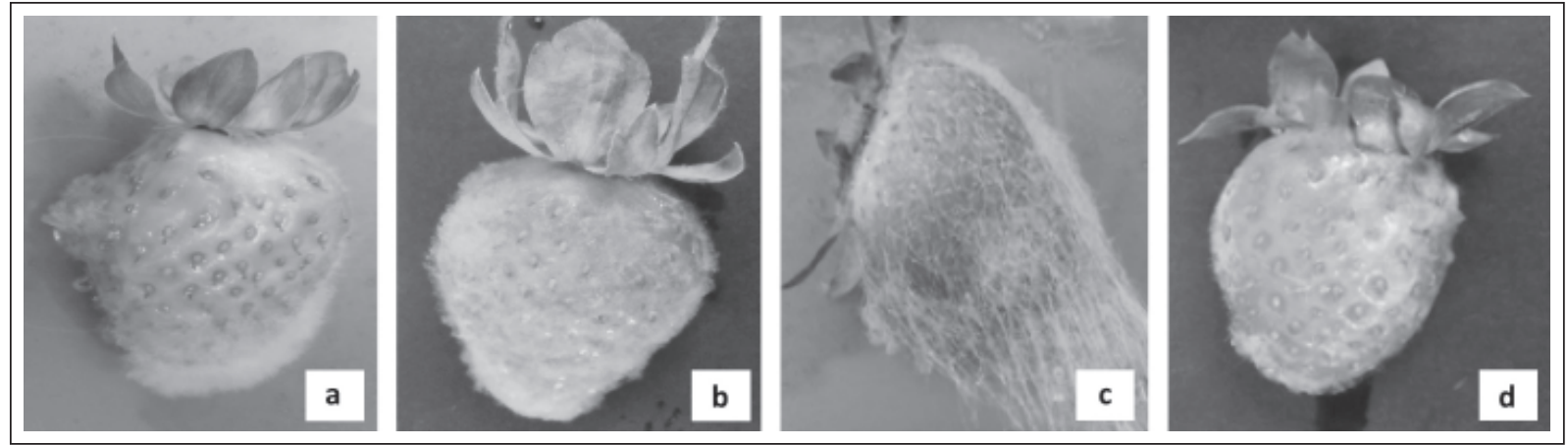

Fig. 7. Harvested strawberries deterioration caused by the fungi Rhizopus stolonifer with different concentration of WEP (a: $0 \%$, b: $10 \%$, c: $12 \%$ and $\mathrm{d}: 14 \%)$.

cottony to brownish-black sporangia) which was assumed as Rhizopus stolonifer disease (Kwon et al., 2009; Feliziani \& Romanazzi, 2016). According to Bajpai et al. (2010), the existence of Rhizopus oligosporus considerably inhibited the growth of the tested pathogens such as Colletotrichum sp. Secondary metabolites produced by Rhizopus oligosporus may suppress the growth of another fungal pathogen (Jeon et al., 2009). However, WEP gives a positive result severity of Rhizopus 
stolonifer disease. Research by Yang et al. (2016) demonstrated the powerful inhibitions against spores germination of Rhizopus stolonifer by propolis.

\section{CONCLUSION}

This study clearly showed that the propolis did not retain most of the post-harvest quality of infected strawberries except firmness but it successfully reduced the occurrence of Colletotrichum gloesporioides by inhibiting mycelium and disease severity. But, this study did not focus on the measurement of ethylene or any parameter that can determine the respiration and ripening, hence any relation of the disease severity on the acceleration of fruit ripening and respiration difficult to be concluded. However, this study can be used as a guideline for future studies on the potential application of propolis as bio-control against Colletotrichum sp. Study using the water extract propolis added with other coating materials such as polysaccharide may help in preserving the postharvest quality of the tested fruits.

\section{ACKNOWLEDGEMENTS}

The authors would like to thank Universiti Malaysia Terengganu for all of the funds and support for the research and also stingless beekeepers for the propolis supply.

\section{REFERENCES}

Ahmad, F.T., Lani, M.N., Nazari, S.A., Hjar, N.H.M., Hassan, K.N.A.M., Razak, S.B.A. \& Hassan, Z. 2019. Antioxidant and antimicrobial properties of honey, propolis and bee bread of stingless bee (Geniotrigona thoracica), Asian Journal of Agriculture and Biology, 1(1): 1-10.

Alves, S.T., Ferreira, I.C., Barros, L., Silva S., Azeredo, J. \& Henriques, M. 2014. Antifungal activity of phenolic compounds identified in flowers from North Eastern Portugal against Candida species. Future Microbiology, 9(2): 139-146.

Anjum, S.I., Ullah, A., Khan, K.A., Attaullah, M., Ali, H., Bashir, M.A., Tahir, M., Ansari, M.J., Ghramh, H.A., Adqaba, N. \& Dash, C.K. 2019. Composition and functional properties of propolis (bee glue): A review. Saudi Journal of Biological Sciences, 27(7): 1695-1703.

Awawdeh, L., AlBeitawi, M. \& Hammad, M. 2009. Effectiveness of propolis and calcium hydroxide as a shortterm intracanal medicament against Enterococcus faecalis: A laboratory study. Australian Endodontic Journal, 35(2): $52-58$

Bajpai, V.K., Choi, S.W. \& Kang, S.C. 2010. Antifungal properties of Rhizopus oligosporus against apple anthracnose fungi. Korean Journal of Environmental Agriculture, 29(1): 86-91.

Barrera, E., Gil, J., Restrepo, A., Mosquera, K. \& Durango, D. 2015. A coating of chitosan and propolis extract for the postharvest treatment of papaya (Carica papaya L. cv. Hawaiiana). Revista Facultad Nacional de Agronomía Medellín, 68(2): 7667-7678.

Bussaman, P., Namsena, P., Rattanasena, P. \& Chandrapatya, A. 2012. Effect of crude leaf extracts on Colletotrichum gloeosporioides (Penz.) Sacc. Psyche, 2012: 1-6.

Chitarra, M.I.F. \& Chitarra, A.B. 2005. Pós-colheita de Frutas e Hortaliças: Fisiologia e Manuseio. 2nd Ed. Universidade Federal de Lavras, Lavras.

Daayf, F. \& Lattanzio, V. 2008. Recent Advances in Polyphenol Research. Wiley-Blackwell, United Kingdom. pp. 221.

Damsa, F., Woinaroschy, A., Olteanu, G., Bãdãrãu, C.L. \& Mãrculescu, A. 2016. Total monomeric anthocyanin and total flavonoid content of processed purple potato. International Journal of Engineering Research and Applications, 6(1): 75-82.

Das, K., Tiwari, R.K.S. \& Shrivastava, D.K. 2010. Techniques for evaluation of medicinal plant products as antimicrobial agent: Current methods and future trends. Journal of Medicinal Plants Research, 4(2): 104-111.

Ellis, M.A. \& Erincik, O. 2008. Anthracnose of strawberry. Department of Plant Pathology, Ohio.

Feliziani, E. \& Romanazzi, G. 2016. Postharvest decay of strawberry fruit: Etiology, epidemiology, and disease management. Journal of Berry Research, 6(1): 47-63.

Guisti, M.M. \& Wrolstad, R.E. 2001. Characterization and measurement of anthocyanins by UV-Visible spectroscopy. Current Protocols in Food Analytical Chemistry, 00(1): F1.2.1F1.2.13.

Jabeen, K. \& Javaid, A. 2008. Antifungal activity of aqueous and organic solvent extracts of allelopathic trees against Ascochyta rabiei. Allelopathy Journal, 22(1): 231-237.

Jeon, H.S., Lokos, L., Han, K.S., Ryu, J.A., Kim, J.A., Koh, Y.J. \& Hur, J.S. 2009. Isolation of lichenforming fungi from Hungarian lichens and their antifungal activity against fungal pathogens of hot pepper anthracnose. Plant Pathology, 25: 38-46. 
Kim, H.J., Lee, E.J., Park, S.H., Lee, H.S. \& Chung, N. 2014. Biological control of anthracnose (Colletotrichum gloeosporioides) in pepper and cherry tomato by Streptomyces sp. A 1022. Journal of Agricultural Science, 6(2): 54-62.

Kwon, J.H., Yoon, H.S., Nam, M.H. \& Park, C.S. 2009. Occurrence of strawberry soft rot by rhizopus stolonifer on distribution after harvest. Korean Journal of Medical Mycology, 37(1): 117-119.

Kososki, R.M., Furlanetto, C., Tomita, C.K. \& Cafe'Filho, A.C. 2001. Efeito de fungicidas em Colletotrichum acutatum e controle da antracnose do morangueiro em campo. Fitopatologia Brasileira, 26: 662-666.

Lane, C.R., Beales, P.A. \& Hughes, K.J.D. 2012. Fungal Plant Pathogens: Principles and Protocols Series. CAB International, Wallingford. $307 \mathrm{pp}$.

López-Castañeda, J., Corrales-García, J., TerrazasSalgado, T. \& Colinas-León, T. 2010. Effect of saturated air heat treatments on weight loss reduction and epicuticular changes in six varieties of cactus pear fruit. Journal of the Professional Association for Cactus Development, 12: 37-47.

Mak, C., Mohamed, A.A., Liew, K.W. \& Ho, Y.W. 2004. Early screening technique for Fusarium wilt resistance in banana micropropagated plants. Banana Improvement, 18: 219-227.

Marinho, G.J.P., Klein, D.E. \& Siqueira, C.L.J. 2018. Evaluation of soapberry (Sapindus saponaria L.) leaf extract against papaya anthracnose. Summa Phytopathologica, 44(2): 127-131.

Meneses, E.A., Durango, D.L. \& García, C.M. 2009. Antifungal activity against postharvest fungi by extracts from Colombian propolis. Química Nova, 32(8): 2011-2017.

Moneruzzaman, K.M., Hossain, A.B.M.S., Sani, W., Saifuddin, M. \& Alenazi, M. 2009. Effect of harvesting and storage conditions on the post harvest quality of tomato (Lycopersicon esculentum Mill) cv. Roma VF. Australian Journal of Crop Science, 3(2): 113.

Park, Y.K., Koo, M.H., Abreu, J.A., Ikegaki, M., Cury, J.A. \& Rosalen, P.L. 1998. Antimicrobial activity of propolis on oral microorganisms. Current Microbiology, 36(1): 24-28.

Paviani, L.C., Saito, E., Dariva, C., Marcucci, M.C. Sánchez-Camargo, A.P. \& Cabral, F.A. 2012. Supercritical $\mathrm{CO}_{2}$ extraction of raw propolis and its dry ethanolic extract. Brazilian Journal of Chemical Engineering, 29(2): 243-251.
Phoulivong, S., Cai, L., Chen, H., McKenzie, E.H., Abdelsalam, K., Chukeatirote, E. \& Hyde, K.D. 2010. Colletotrichum gloeosporioides is not a common pathogen on tropical fruits. Fungal Diversity, 44(1): 33-43.

Priyadarshanie, H.K.R. \& Vengadaramana, A. 2015. Some Preliminary Studies of Colletotrichum musae associated with banana anthracnose disease in Jaffna district, Sri Lanka. Universal Journal of Agricultural Research, 3(6): 197-202

Qadir, M.A.Q., Shahzadi, S.K., Bashir, A., Munir, A. \& Shahzad, S. 2017. Evaluation of phenolic compounds and antioxidant and antimicrobial activities of some common herbs. International Journal of Analytical Chemistry, 2017: 1-6.

Ribeiro, C., Vicente, A.A., Teixeira, J.A. \& Miranda, C. 2007. Optimization of edible coating composition to retard strawberry fruit senescence. Postharvest Biology and Technology, 44: 6370.

Sun, C., Wu, Z., Wang, Z. \& Zhang, H. 2015. Effect of ethanol/water solvents on phenolic profiles and antioxidant properties of Beijing propolis extracts. Evidence- Based Complementary and Alternative Medicine, 2015: 1-9.

Suzuki, T., Tanaka-Miwa, C., Ebihara, Y., Ito, Y. \& Uematsu, S. 2010. Genetic polymorphism and virulence of Colletotrichum gloeosporioides isolated from strawberry (Fragaria $\times$ ananassa Duchesne). Journal of General Plant Pathology, 76(4): 247-253.

Thomas, A.B., Nassur, R.C., Boas, A.C.V. \& Lima, L.C. 2016. Cassava starch edible coating incorporated with propolis on bioactive compounds in strawberries. Ciência e Agrotecnologia, 40(1): 87-96.

Viuda Martos, M., Ruiz Navajas, Y., Fernández López, J. \& Pérez Álvarez, J.A. 2008. Functional properties of honey, propolis, and royal jelly. Journal of Food Science, 73(9): R117-R124.

Yang, S., Zhou, Y., Ye, J., Fan, G., Peng, L. \& Pan, S. 2016. Effects of poplar buds as an alternative to propolis on postharvest diseases control of strawberry fruits. Journal of the Science of Food and Agriculture, 96(6): 2136-2141.

Zahid, N., Ali, A., Siddiqui, Y. \& Maqbool, M. 2013. Efficacy of ethanolic extract of propolis in maintaining postharvest quality of dragon fruit during storage. Postharvest Biology and Technology, 79: 69-72. 